\title{
Novel intracellular antibiotic delivery system against Staphylococcus aureus: cloxacillin-loaded poly(D, L-lactide-co-glycolide) acid nanoparticles
}

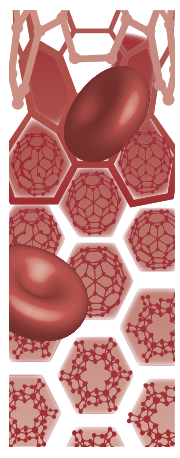

\author{
Alicia Lacoma*,‡,1,2 (iD), Laura Usón ${ }^{\ddagger 3,4}$, Gracia Mendoza ${ }^{3,4}$, Victor Sebastián ${ }^{3,4}$, Esther \\ Garcia-Garcia1， Beatriz Muriel-Moreno1， Jose Domínguez $z^{\ddagger 1,1,2}$, Manuel Arruebo ${ }^{\ddagger \ddagger, 3,4}$ \& \\ Cristina Prat $\$ \ddagger, 1,2,5$ \\ ${ }^{1}$ Microbiology Department, Hospital Universitari Germans Trias i Pujol, Fundació Institut d'Investigació en Ciències de la Salut \\ GermansTrias i Pujol, Universitat Autònoma de Barcelona, Badalona, Spain \\ ${ }^{2}$ CIBER Enfermedades Respiratorias (CIBERES), Instituto de Salud Carlos III, Spain \\ ${ }^{3}$ Institute of Nanoscience of Aragon (INA), Department of Chemical Engineering \& Environmental Technologies, University of \\ Zaragoza \& Instituto de Ciencia de Materiales de Aragón (ICMA), Universidad de Zaragoza-CSIC, 50018, Zaragoza, Spain \\ ${ }^{4}$ CIBER Bioingeniería, Biomateriales y Nanomedicina (CIBER-BBN), Instituto de Salud Carlos III, Spain \\ ${ }^{5}$ Julius Centre for Health Sciences and Primary Care, University Medical Center Utrecht, Utrecht University, Utrecht, The Netherlands \\ *Author for correspondence: Tel.: +34 9349788 94; Fax: +34 9349788 95; alacoma@igtp.cat \\ ${ }_{\ddagger}^{\ddagger}$ Authors contributed equally \\ $\ddagger$ Co-senior authors
}

Aim: First, to compare in vitro minimum inhibitory concentrations (MIC) of free cloxacillin and cloxacillincontaining nanoparticles (NP) against methicillin-susceptible (MSSA) and resistant Staphylococcus aureus (MRSA) and second, to assess NP antimicrobial activity against intracellular S. aureus. Methods: Poly(D,L-lactide-co-glycolide) acid (PLGA)-NP were loaded with cloxacillin and physico-chemically characterized. MICs were determined for reference strains Newman-(MSSA) and USA300-(MRSA). Murine alveolar macrophages were infected, and bacterial intracellular survival was assessed after incubating with free-cloxacillin or PLGA-cloxacillin-NP. Results \& conclusion: For both isolates, MICs for antibiotic-loadedNP were lower than those obtained with free cloxacillin, indicating that the drug encapsulation improves antimicrobial activity. A sustained antibiotic release was demonstrated when using the PLGA-cloxacillinNP. When considering the lowest concentrations, the use of drug-loaded NP enabled a higher reduction of intracellular bacterial load.

\section{Graphical abstract:}

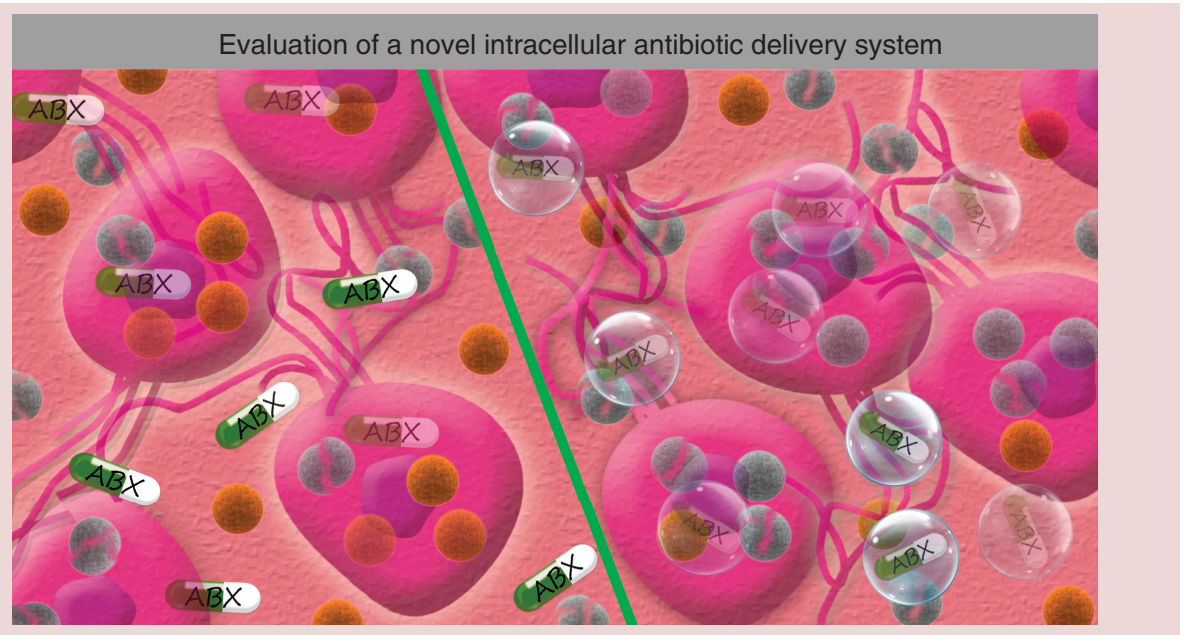


First draft submitted: 2 October 2019; Accepted for publication: 17 March 2020; Published online: 6 May 2020

\section{Keywords: antimicrobial $\bullet$ drug delivery $\bullet$ intracellular infection $\bullet$ nanoparticle $\bullet$ Staphylococcus aureus}

Staphylococcus aureus is a major human pathogen responsible for a spectrum of diseases, which can manifest in a range of ways from asymptomatic carriage to life threatening infections [1]. Methicillin-resistant S. aureus (MRSA) were included in the 12 antibiotic-resistant priority pathogens listed by the World Health Organization (WHO) in 2017 [2]. The prevalence of MRSA varies geographically with a population-weighted mean percentage of 16.9\% with large differences ranging between $1 \%$ in Norway to $44.4 \%$ in Romania (25.3\% in Spain) [3]. The spread of MRSA in healthcare and community settings is raising concern because of its impact on morbidity and mortality and high economic burden due to longer length of in-hospital stays, the need for contact isolation precautions and decolonization strategies. Cloxacillin is the first line antimicrobial for the treatment of methicillin-susceptible staphylococcal infections because of its intrinsic properties: bactericidal effect, efficient tissue distribution and safety profile [4].

S. aureus is present in the upper respiratory tract of approximately $30 \%$ of healthy individuals and it can potentially become an airway pathogen in certain groups of patients [5]. Additionally, MRSA decolonization is particularly ineffective in the respiratory tract [6]. We have recently reported persistent $S$. aureus isolation in respiratory samples despite adjusted antibiotic treatment with no correlation with an adverse clinical outcome [7]. In this context, several aspects related to biofilm formation or drug delivery in the lung need to be taken into consideration, but importantly $S$. aureus can be found intracellularly in different eukaryotic cell types and not only localized in the extracellular milieu. Their interaction with professional phagocytes (neutrophils, macrophages, dendritic cells) [8,9] and nonprofessional phagocytes (e.g., endothelial/epithelial cells, osteoblasts and keratinocytes) [10] has been extensively documented. In the case of macrophages, S. aureus subcellular localization has been described according to the host cell type and the bacterial strain tested. Indeed, $S$. aureus has been localized in vacuoles, endosomes, cytoplasm, phagolysosomes and in the compartments of the autophagic pathway $[9,11,12]$. Regardless of the strategy considered, this intracellular localization represents a privileged niche and a bacterial reservoir which is protected from the antimicrobial activity of antibiotics [13] and the immunological host defense mechanisms.

Current approaches for the treatment of infectious diseases are directed toward the development of nanosystems (i.e., nanoparticles [NPs]) producing a controlled or sustained release of encapsulated antimicrobials. The NP acts as a drug carrier in the form of suspensions or as coatings on medical devices. In some cases, the NP does not act as a drug carrier but presents antimicrobial properties of its own (e.g., nanosilver) with a release of ionic species that can have multiple mechanisms of bactericidal action. It is well known that when multiple mechanisms of action take place against bacteria, it is difficult for simultaneous gene mutations to occur and therefore the development of resistance is hindered. General applications include biocompatible NPs used as adjuvants and antimicrobial or vaccine carriers in order to achieve a sustained or controlled delivery during infections and to promote an immune response during vaccine delivery [14]. In addition, nanoparticles offer the potential to achieve a targeted and selective delivery of the corresponding antimicrobial drug intracellularly, where the responsible bacteria/virus are located, without altering the surrounding commensal microbiota [15]. Intracellular delivery requires the use of materials that can bind and recognize the eukaryotic cell membrane. Passive strategies take advantage of recognition by the immune system, as macrophages can recognize and internalize NPs naturally by an energy-dependent phagocytic mechanism [16]. Therefore, the antimicrobial cargos of NPs can accumulate inside intracellular compartments of infected cells, which can later fuse with pathogen containing vesicles or release the NP payload into the cytoplasm. The introduction of targeted drug-delivery systems that respond to the acidic $\mathrm{pH}$ of the endolysosomal compartments are specially designed to target pathogens with an intracellular lifestyle, such as Mycobacterium tuberculosis, but also species that have been described as facultative intracellular pathogens more recently, such as Pseudomonas aeruginosa and S. aureus [14]. We have recently designed a drug-delivery system intended for oral administration to access $M$. tuberculosis infected alveolar macrophages using biodegradable and approved rifampicin-loaded nanoparticulate carriers [17]. Rifampicin was loaded inside poly(D,L-lactide-co-glycolide) acid (PLGA) NPs, which were subsequently loaded into gastro-protected microcapsules to improve drug bioavailability. We postulated that intracellular accumulation and slow antibiotic release could be achieved when using orally administered antibiotic-loaded PLGA-NPs if they were able to cross the intestinal epithelium into the bloodstream with a sufficient blood circulation half-life to reach infected alveolar macrophages. In the current work, the delivery 
system designed is based on nanoparticulated formulations of PLGA (Resomer RG504) NP loaded with cloxacillin and we again postulate that a potential co-localization between the drug-loaded nanoparticle and the bacteria in the same intracellular compartment could enhance the antimicrobial efficiency of the drug. The main objectives of this study were: To determine the in vitro minimum inhibitory concentrations (MICs) of drug-containing nanoparticles required against methicillin-susceptible (MSSA) and resistant (MRSA) S. aureus compared with the corresponding concentration of the free drug, and to assess the antimicrobial activity of drug containing nanoparticles against intracellular $S$. aureus in a cell infection model using alveolar macrophages.

\section{Material \& methods}

Nanoparticle synthesis \& characterization

Resomer ${ }^{\circledR}$ RG504, an ester terminated PLGA 50:50 (Mw: 38,000-54,000 Da) was purchased from Evonik Industries AG (Darmstadt, Germany). Cloxacillin sodium salt and dexamethasone (as an internal standard for the HPLC determination), Pluronic ${ }^{\circledR}$ F-68,ethyl acetate, ethanol absolute, acetonitrile and methanol (HPLC grade) were supplied by Sigma-Aldrich (MO, USA).

PLGA-cloxacillin nanoparticles were prepared by the oil-in-water $(\mathrm{O} / \mathrm{W})$ single emulsion solvent evaporation method. $50 \mathrm{mg}$ of PLGA polymer, $40 \mathrm{mg}$ of cloxacillin and $150 \mathrm{mg}$ of Pluronic F68 (as surfactant), were dissolved in $5 \mathrm{ml}$ of ethyl acetate. The organic phase was then emulsified with $10 \mathrm{ml}$ of Milli Q water and sonicated in an ice bath for $25 \mathrm{~s}$ with a sonicator (Digital Sonifier 450, MO, USA) using a probe of 0.13 inches in diameter and $40 \%$ of amplitude. The organic solvent of the resulting emulsion was evaporated under stirring $(600 \mathrm{rpm}, 3 \mathrm{~h})$ and the obtained nanoparticles were washed by centrifugation twice and redispersed in $2 \mathrm{ml}$ of Milli Q water. Cloxacillin sodium salt was previously protonated at $\mathrm{pH}=2$ to render it hydrophobic $(\mathrm{pKa}=2.7)$ in order to increase the drug loading.

The hydrodynamic diameter of the colloidal drug-loaded nanoparticles at a $\mathrm{pH}$ of 7.4 was determined by dynamic light scattering in a Brookhaven 90 Plus system (NY, USA). Their morphological characterization was analyzed using scanning electron microscopy (SEM; Inspect ${ }^{\mathrm{TM}} \mathrm{F} 50$ Scanning Electron Microscope, Holland, FEI) and transmission electron microscopy (TEM; TECNAI FEI T20). The nanoparticles for TEM analysis were stained with 7\% (w/v) phosphotungstic acid as a negative contrast. Fourier transform infrared spectroscopy (FTIR) was carried out to evaluate the potential molecular interactions between the encapsulated antibiotic and the encapsulating polymer using a Bruker Vertex 70 (Bruker Corporation, USA).

The drug content in the resulting NP was determined by HPLC (Waters 2695, RP column Phenomenex Kinetex, $4.6 \times 50 \mathrm{~mm}, 2.6 \mu \mathrm{m}$ ) as follows: $100 \mu \mathrm{l}$ of the corresponding drug-loaded NP suspension was centrifuged at $13,250 \times \mathrm{g}$. The pellet obtained was dissolved in $1.15 \mathrm{ml}$ of acetonitrile and mixed for $1 \mathrm{~h}$ with $100 \mu \mathrm{l}$ of dexamethasone. Then, $250 \mu \mathrm{l}$ of methanol was added to promote PLGA precipitation. The dispersion was then centrifuged at $19,000 \times g$ to remove the polymeric residue and the supernatant was filtered ( $0.22 \mu \mathrm{m}$ cut-off) and analyzed in triplicate. Quantification was also carried out by a seven-point calibration against the internal standard. The analyte was detected at $225 \mathrm{~nm}$. The linearity range was 10 to $200 \mathrm{ppm}\left(\mathrm{r}^{2}=0.9992\right)$ and the limit of detection and limit of quantitation were 7 and $21 \mathrm{ppm}$, respectively.

Drug encapsulation was expressed both as drug loading (DL) and entrapment efficiency (EE), and they were calculated using the following equations:

$$
\begin{gathered}
\text { DL }(\%)=\frac{(\text { weight of drug entrapped })}{(\text { total weight of drug }- \text { loaded nanoparticles })} \times 100 \\
\text { EE }(\%)=\frac{(\text { weight of drug entrapped })}{(\text { total weigth of drug added })} \times 100
\end{gathered}
$$

Drug release studies were carried out by incubating the antibiotic-loaded nanoparticles at $37^{\circ} \mathrm{C}$ in an orbital shaker (90 rpm). The $250 \mu \mathrm{l}$ of different cloxacillin-loaded nanoparticle batches $(15 \mathrm{mg} / \mathrm{ml})$ were incubated in water at $\mathrm{pH} 7$ in order to elucidate the drug release kinetic constant and order. At different times, $200 \mu \mathrm{l}$ of supernatants were collected, after centrifugation during $8 \mathrm{~min}$ at $5300 \times \mathrm{g}$, and chromatographically analyzed and replaced with distillate water. 
For microscopy analysis, Red Nile (RN)-PLGA nanoparticles were prepared using the single emulsionprecipitation method using the same protocol and experimental conditions described above for the encapsulation of cloxacillin by dissolving $5 \mu \mathrm{g}$ of the fluorescent dye in the ethyl acetate.

\section{Minimum inhibitory concentration}

S. aureus Newman strain (MSSA) and USA300 (MRSA) were tested. Bacteria were routinely cultivated in Mueller Hinton $(\mathrm{MH})$ agar at $37^{\circ} \mathrm{C}(\mathrm{pH} 7)$. Nanoparticles (empty and cloxacillin loaded) and free antibiotic were tested against both strains by the broth microdilution method in 96-well microplates. The formulations were serially diluted twofold in $\mathrm{MH}$ broth cation adjusted from a starting concentration of $0.0078 \mu \mathrm{g} / \mathrm{ml}$ to $8 \mu \mathrm{g} / \mathrm{ml}$ in a final volume of $100 \mu$ l. Empty PLGA NP, PLGA-cloxacillin NP and free cloxacillin were prepared in MH cation adjusted media at three different $\mathrm{pHs}(\mathrm{pH} 4.5, \mathrm{pH} 5.5$ and $\mathrm{pH}$ 7) to assess the influence of acidic $\mathrm{pH}$ on the release of the drug from the antimicrobial loaded NPs. Then, $1 \mu \mathrm{l}$ of $S$. aureus inoculum was added to each well to produce a bacterial cell concentration of $5 \times 10^{5} \mathrm{cfu} /$ well. Plates were incubated for $24 \mathrm{~h}$ at $37^{\circ} \mathrm{C}$. Negative (absence of bacteria and antimicrobial) and positive (presence of bacteria and absence of antimicrobial) growth controls were included in each plate. The minimum inhibitory concentration (MIC) was defined as the lowest concentration that can prevent visible bacterial growth. We assume that all bacteria were in planktonic form and no biofilm was formed. We followed Clinical and Laboratory Standards Institute (CLSI) Guidelines. Assays were run in triplicate.

\section{Bacterial morphology after treatment with free drug \& PLGA-cloxacillin NP}

To determine the effects of NP treatment, bacteria morphology was studied by SEM, as previously reported [18]. In brief, free cloxacillin and PLGA-cloxacillin NP (at respective MIC and 0.5 MIC) were added to S. aureus Newman and USA 300 strain cultures (final volume $1 \mathrm{ml}$, bacterial concentration: $5.10^{6} \mathrm{cfu} / \mathrm{ml}$ ) and incubated overnight under shaking $\left(180 \mathrm{rpm}, 37^{\circ} \mathrm{C}\right)$.

Then, bacterial samples were washed twice (PBS $0.1 \mathrm{M}$ ) and fixed in glutaraldehyde (2.5\%; $90 \mathrm{~min})$. After fixation, samples were dehydrated in ethanol series (30-100\%; twice for $15 \mathrm{~min}$ ), air-dried and finally coated with $\mathrm{Pt}(15 \mathrm{~nm})$ for electron microscopy imaging. SEM micrographs were recorded in a SEM Inspect F50 at 10-15 keV (FEI Co., LMA-INA, Spain).

\section{Cytotoxicity assay}

Murine alveolar macrophages (MH-S; ATTC, CRL-2019) were grown in Roswell Park Memorial Institute (RPMI)1640 tissue culture medium supplemented with $10 \%$ heat-inactivated calf serum (FCS), Hepes $10 \mathrm{mM}$ and antibiotics/antifungals at $37^{\circ} \mathrm{C}$ in a humidified atmosphere and $5 \% \mathrm{CO}_{2}$. To determine the cytotoxic effect of PLGA nanoparticles on MH-S, Presto Blue reagent (Invitrogen) was used following the manufacturer's instructions. Briefly, MH-S were seeded at a concentration of $1 \times 10^{5}$ cells per well in 96-well tissue culture in a final volume of $200 \mu \mathrm{l}$ and incubated overnight. Empty PLGA nanoparticles, PLGA-cloxacillin nanoparticles and free cloxacillin were diluted in $100 \mu \mathrm{l}$ of RPMI supplemented with $10 \%$ FCS. Two concentrations of cloxacillin (free and encapsulated, respectively) were tested: 70 and $100 \mu \mathrm{g} / \mathrm{ml}$. These values are below the observed maximal concentration $\left(\mathrm{C}_{\max }\right)$ in serum after intravenous/oral administration of conventional doses to humans [19]. The monolayers were washed twice with PBS and then $100 \mu \mathrm{l}$ of fresh medium and $10 \mu \mathrm{l}$ of Presto Blue were added. Plates were incubated for $1 \mathrm{~h}\left(37^{\circ} \mathrm{C}\right.$ in $5 \% \mathrm{CO}_{2}$ atmosphere) and after that, the fluorescence was recorded in a microplate reader (Varioskan, Thermo Fisher Scientific) at $560 \mathrm{~nm}$ excitation and $590 \mathrm{~nm}$ emission. The viability was calculated by linear interpolation of the fluorescence data from the cells treated with the different combinations versus the nontreated ones.

\section{Invasion protocol}

Cells were seeded in 24-well tissue culture plates at $5.10^{5}$ cells per well $24 \mathrm{~h}$ before the experiment. Newman and USA300 S. aureus strains were grown in $5 \mathrm{ml}$ of LB liquid media and harvested in the exponential phase $(2500 \times \mathrm{g}, 20 \mathrm{~min})$, washed once with PBS, and resuspended. A suspension containing approximately $5.10^{8} \mathrm{cfu} / \mathrm{ml}$ was prepared in PBS. Cells were infected with $25 \mu \mathrm{l}$ of this suspension to get a multiplicity of infection (MOI) of $25: 1$ in a final volume of $500 \mu \mathrm{l}$ of RPMI 1640 tissue culture medium supplemented with $10 \%$ FCS and Hepes $10 \mathrm{mM}$. To synchronize infection and thus facilitate the contact between adhered cells and bacteria, plates were centrifuged at $200 \times g$ for $5 \mathrm{~min}$. Plates were incubated at $37^{\circ} \mathrm{C}, 5 \% \mathrm{CO}_{2}$ for $30 \mathrm{~min}$. This time is sufficient to ensure that bacteria are taken up by cells, as shown in our previous paper [11]. After that, cells were washed 
five-times with PBS and incubated for $1 \mathrm{~h}$ with $500 \mu \mathrm{l}$ RPMI 1640 containing 10\% FCS, Hepes $10 \mathrm{mM}$, gentamicin $(200 \mathrm{mg} / \mathrm{ml})$ to remove extracellular bacteria. After $1 \mathrm{~h}$ of contact with gentamicin, different treatment combinations (free/encapsulated drug at selected concentrations) were added. Cells were washed twice and fresh medium containing PLGA NP, PLGA-cloxacillin NP or free cloxacillin were added at a range of concentrations including: MIC, $10 \times$ MIC respectively for each bacterial strain until the end of the experiment. To determine intracellular bacterial load at selected time points $(3.5 \mathrm{~h}$ and $24.5 \mathrm{~h}$ post infection), cells were then washed threetimes with PBS and lysed with $300 \mathrm{ml}$ of $0.025 \%$ saponin in PBS for $10 \mathrm{~min}$ at room temperature. Serial dilutions were plated on LB agar to quantify the number of intracellular bacteria. Data are represented as $\log 10$ cfu per well. All experiments were done in triplicates on at least three independent occasions.

\section{Immunofluorescence microscopy}

GFP-Newman strain was grown in LB in the presence of erythromycin $(10 \mu \mathrm{g} / \mathrm{ml})$ and later prepared as in the previous section (Invasion protocol). Cells were seeded on $12 \mathrm{~mm}$ circular coverslips in 24-well tissue culture plates. Infections were performed as described before for performing intracellular bacterial counts. After $1 \mathrm{~h}$ of incubation with gentamycin $(200 \mu \mathrm{g} / \mathrm{ml})$, RN-PLGA nanoparticles $(1.25 \mu \mathrm{g} / \mathrm{ml})$ were added to the cell culture wells. When indicated, cells were washed three-times with PBS, and fixed with 3.7\% paraformaldehyde in PBS (pH 7.4) for $15 \mathrm{~min}$. Host cell nuclei were stained with Hoechst $33342(2.5 \mu \mathrm{g} / \mathrm{m}$; Invitrogen). Finally, coverslips were washed twice in PBS and mounted on Aqua Poly/Mount (18606, Polysciences). Specimens were observed with an inverted fluorescence microscope Zeiss AxioObserver Z1 coupled to a monochrome AxioCam MRc 5 camera with the specific Zen Blue 2012, software for image acquisition and analysis.

\section{Statistical analysis}

Statistical analyses were performed using the GraphPad PRISM 7.0 software package (CA, USA). Mean differences between conditions were compared by the two-way ANOVA. A p-value $\leq 0.05$ was considered statistically significant.

\section{Results}

Nanoparticles characterization

Figure 1A depicts an SEM image of the resulting PLGA-cloxacillin NP, exhibiting a typical spherical shape. The particle size distribution histogram shows that a narrow particle size distribution was achieved, resulting in a mean diameter value of $106.5 \mathrm{~nm} \pm 24 \mathrm{~nm}$ (Figure 1B). TEM images of negatively stained PLGA-cloxacillin NPs also revealed the production of monodisperse particles, as well as the lack of nonencapsulated cloxacillin crystals surrounding the PLGA spherical nanoparticles (Figure 1C \& D). HPLC analysis revealed a drug loading and an encapsulation efficiency of $20.5 \pm 1.2 \%$ and $18.9 \pm 2.7 \%$, respectively. FTIR analysis (Figure $1 \mathrm{E}$ ) revealed that no chemical interaction between the drug and the PLGA carrier was found which indicates that the physiological effect of the drug would not be impaired by its encapsulation within the polymeric PLGA-based matrix. As colloidal water-based suspensions were used, the resulting PLGA-cloxacillin NP showed a hydrodynamic diameter of $123 \pm 13 \mathrm{~nm}$ (Figure $1 \mathrm{~F}$ ). The subpopulation on the left side of $\mathrm{x}$-axis corresponds to broken nanoparticles and polymer leftovers. These data are in agreement with the literature, where DLS particle size measurements are usually larger than those obtained with electronic microscopy because DLS takes into account the interaction of the nanoparticle with water (i.e., solvation layer) providing the hydrodynamic diameter and microscopy imaging is carried out in a water free environment under vacuum [20]. The $\zeta$ potential of PLGA-cloxacillin nanoparticles at $\mathrm{pH}$ of 7.4 was $-12.5 \pm 3 \mathrm{mV}$. Drug release data at $37^{\circ} \mathrm{C}$ were fitted into three different kinetic models: zero order, first order and Higuchi diffusion model. The correlation coefficients for the three models showed values of 0.815 , 0.995 and 0.965 , respectively. Hence, the release of cloxacillin fits a first-order $(\mathrm{k}=0.488 \mathrm{~h}-1)$ cumulative drug release of 79 wt. $\%$ in the first $24 \mathrm{~h}$ (Figure $1 \mathrm{G}$ ).

\section{MIC determination}

To examine the antimicrobial effect of PLGA-cloxacillin in comparison with free cloxacillin, MIC values were calculated against a methicillin-susceptible strain (Newman) and a methicillin-resistant strain (USA300) at three different pHs (4.5, 5.5 and 7) (Figure 2A: MSSA; Figure 2B: MRSA). For both strains, MICs for PLGA-cloxacillin were lower than those of free cloxacillin suggesting that drug encapsulation improves antimicrobial activity. The reduction of MICs was observed at acid and neutral $\mathrm{pH}$ and it ranged from two- to fourfold. Interestingly for the 
(A)

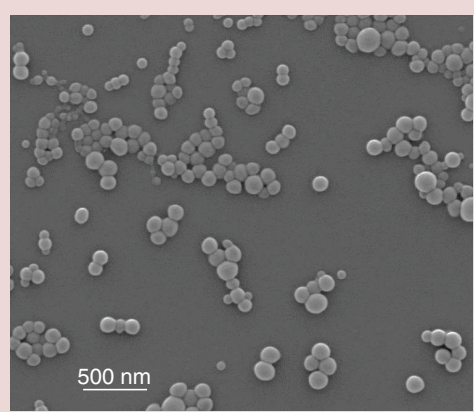

(C)

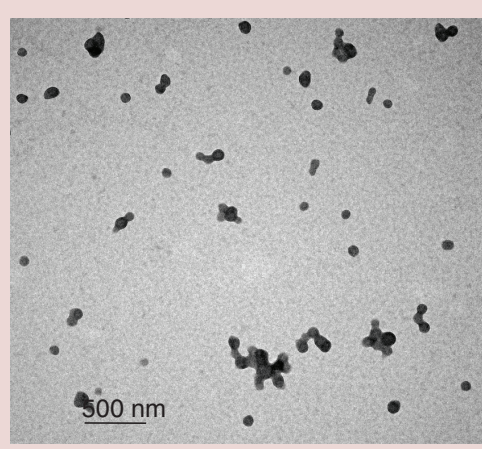

(E)

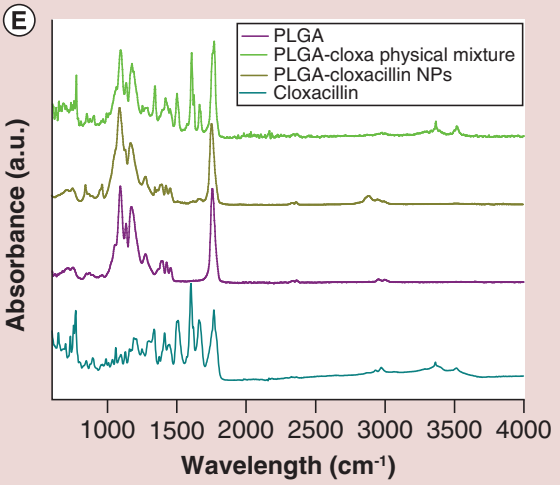

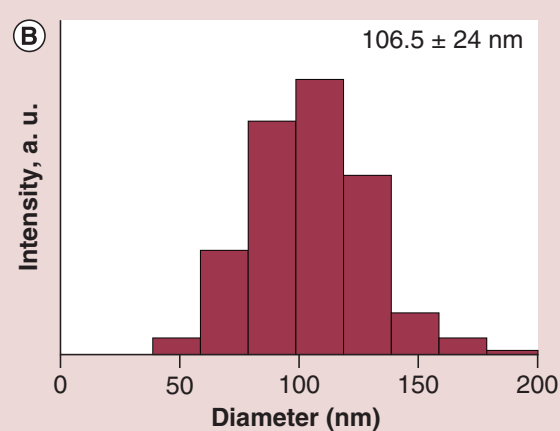

(D)

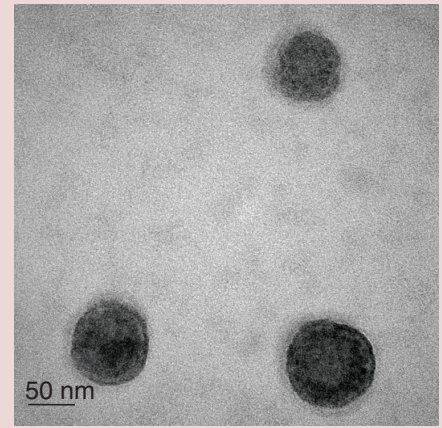

(

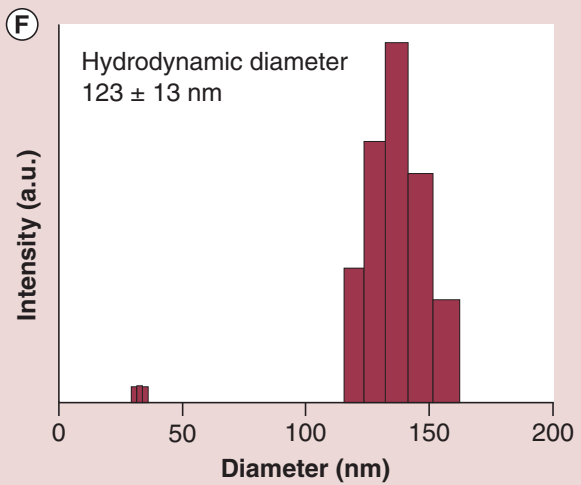

(a)

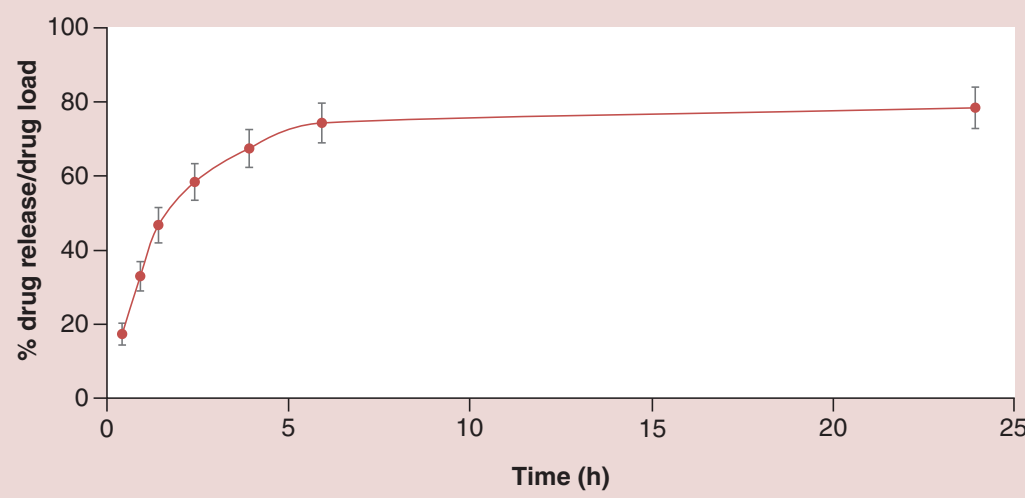

Figure 1. Poly(D,L-lactide-co-glycolide)-cloxacillin nanoparticle characterization. (A) Scanning electron microscopy image; (B) particle size distribution histogram obtained after the measurement of more than $200 \mathrm{NPs}$ from scanning electron microscopy images; (C) transmission electron microscopy image of negatively stained NP; (D) detailed transmission electron microscopy image to show PLGA-cloxacillin NP with a high magnification; (E) Fourier-transform infrared spectroscopy of cloxacillin loaded in PLGA NP and physically mixed with PLGA polymer; (F) particle size distribution histogram obtained by dynamic light scattering measurement; (G) cumulative drug release kinetics of cloxacillin loaded PLGA nanoparticles at $37^{\circ} \mathrm{C}$ at pH 7. NP: Nanoparticle; PLGA: Poly(D,L-lactide-co-glycolide). 

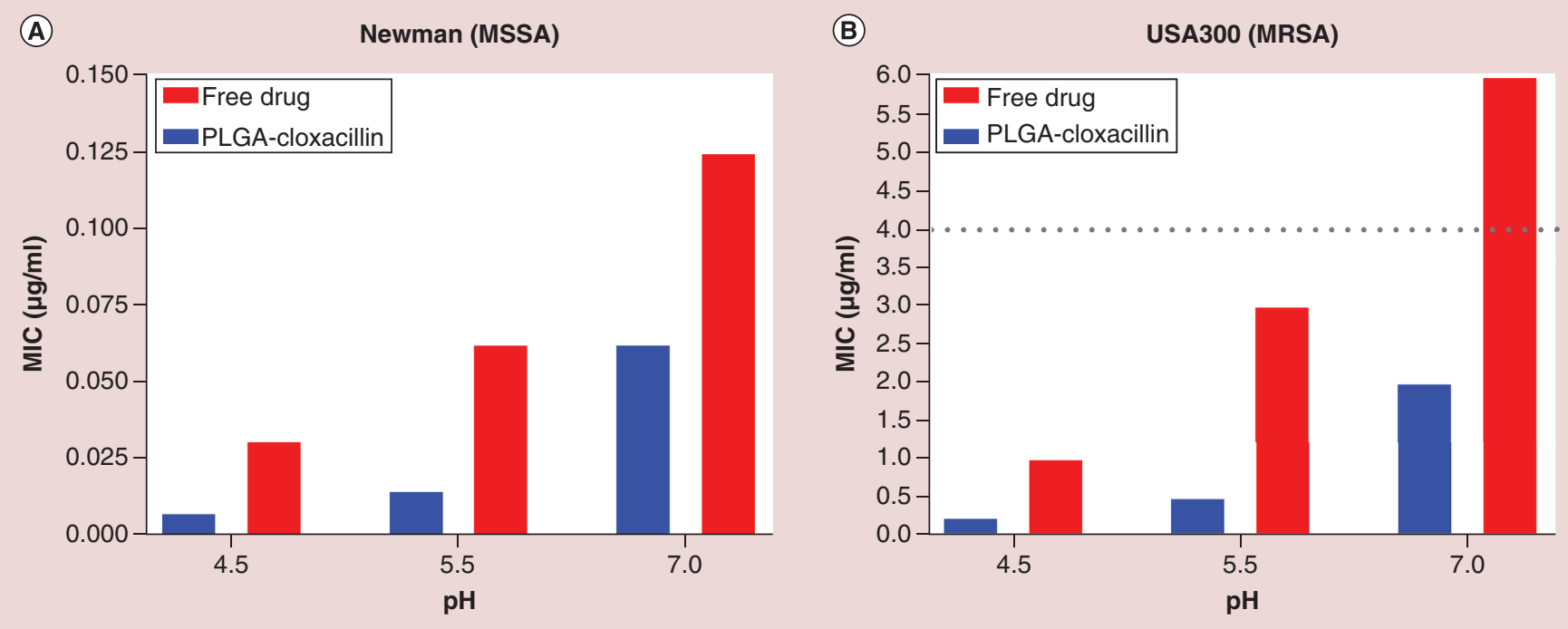

Figure 2. Minimum inhibitory concentration results. MIC values for free-cloxacillin and PLGA-cloxacillin according to strain (A) Newman; (B) USA300 and pH tested (4.5, 5.5 and 7).

MIC: Minimum inhibitory concentration; MRSA: Methicillin-resistant Staphylococcus aureus; MSSA: Methicillin-susceptible Staphylococcus aureus; PLGA: Poly(D,L-lactide-co-glycolide).

MRSA strain, the use of the encapsulated drug at neutral $\mathrm{pH}$ enabled the classification of the strain as methicillinsusceptible in comparison to free cloxacillin, and at acidic $\mathrm{pH}$, MICs for PLGA-cloxacillin and free cloxacillin were lower than $3 \mu \mathrm{g} / \mathrm{ml}$. Empty PLGA nanoparticles had no inhibitory activity on bacterial growth.

In Figure 3, SEM images obtained after overnight culture of both bacterial strains (Figure 3A: MSSA; Figure 3B: MRSA) with free drug or with PLGA-cloxacillin loaded NPs at different concentrations (MIC and 0.5MIC) are shown. For both strains, bacteria grown in $\mathrm{MH}$ have a similar shape and roughness. The treatment with cloxacillin, either free or encapsulated, enhanced changes in cell morphology with the observation of shallow or even deep grooves and the loss of the cell morphology (Figure 3B). Furthermore, these changes involved a size increase which was dose dependent, which is a typical effect of cell wall damage [18].

\section{PLGA cytotoxicity \& invasion experiments}

Cell viability on murine alveolar macrophages was not affected by the use of PLGA nanoparticles (empty or loaded) at both concentrations tested (Figure 4). Free cloxacillin was also tested, and no cytotoxicity was reported at the doses tested either.

MH-S cells were infected with the Newman strain and after 1-h incubation with gentamicin $(200 \mu \mathrm{g} / \mathrm{ml})$ to eliminate non-phagocytozed bacteria three different concentrations of cloxacillin were tested: MIC $(0.125 \mu \mathrm{g} / \mathrm{ml})$, $10 \times$ MIC $(1.25 \mu \mathrm{g} / \mathrm{ml})$ and $8 \mu \mathrm{g} / \mathrm{ml}$. Every concentration was prepared both as free drug and as drug loaded PLGA NP. Intracellular bacterial $\operatorname{load}(\log 10 \mathrm{cfu} /$ well) according to the concentration tested and time point considered are shown in Figure 5A. There is a reduction of intracellular bacterial load with time for all conditions, except for the lowest concentration tested. For free-cloxacillin $(0.125 \mu \mathrm{g} / \mathrm{ml})$, an increase in the bacterial load at $24 \mathrm{~h}$ post infection (p.i.) was observed, whereas for the same concentration when using PLGA-cloxacillin a slight decrease was observed. There was almost an overlap between counts at $24.5 \mathrm{~h}$ p.i. for 1.25 and $8 \mu \mathrm{g} / \mathrm{ml}$ (free and PLGA-cloxacillin), although the highest reduction was reported for the highest concentration (regardless of whether encapsulated, or the free drug was used). Figure 6 shows that GFP-S. aureus has been internalized in some cells during the invasion experiment, as well as RN-PLGA nanoparticles. In some cells, there is colocalization between bacteria and nanoparticles whereas in other cells, nanoparticles are distributed in the cytoplasm, probably in compartments of the endosomal-lysosomal route.

Similarly, MH-S cells were infected with USA300 using the same protocol as described above. Drug concentrations tested were: $6 \mu \mathrm{g} / \mathrm{ml}$ (MIC), and $60 \mu \mathrm{g} / \mathrm{ml}(10 \times \mathrm{MIC})$ for free cloxacillin and PLGA-cloxacillin (Figure 5B). For $6 \mu \mathrm{g} / \mathrm{ml}$, the reduction of the intracellular bacterial load was higher when using PLGA-loaded nanoparticles in 


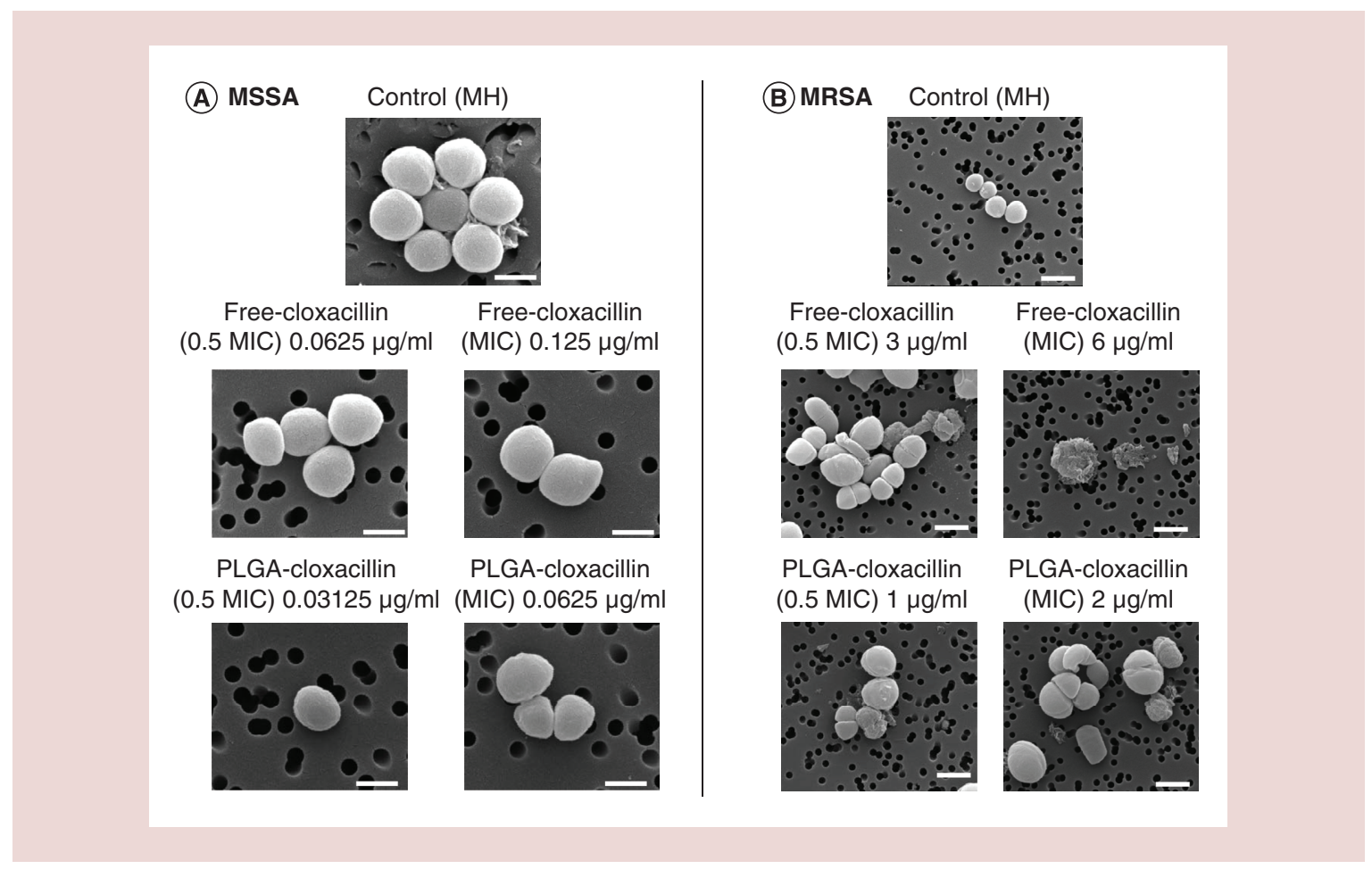

Figure 3. Scanning electron microscopy micrographs showing bacterial morphology. (A) Newman; (B) USA300 after treatment with free-cloxacillin and PLGA-cloxacillin (MIC; $0.5 \mathrm{MIC}$ ). Scale bar in micrographs $\mathrm{a}=500 \mathrm{~nm} ; \mathrm{b}=1 \mu \mathrm{m}$. MH: Mueller Hinton; MIC: Minimum inhibitory concentration; MRSA: Methicillin-resistant Staphylococcus aureus; MSSA: Methicillin-susceptible Staphylococcus aureus; PLGA: Poly(D,L-lactide-co-glycolide).

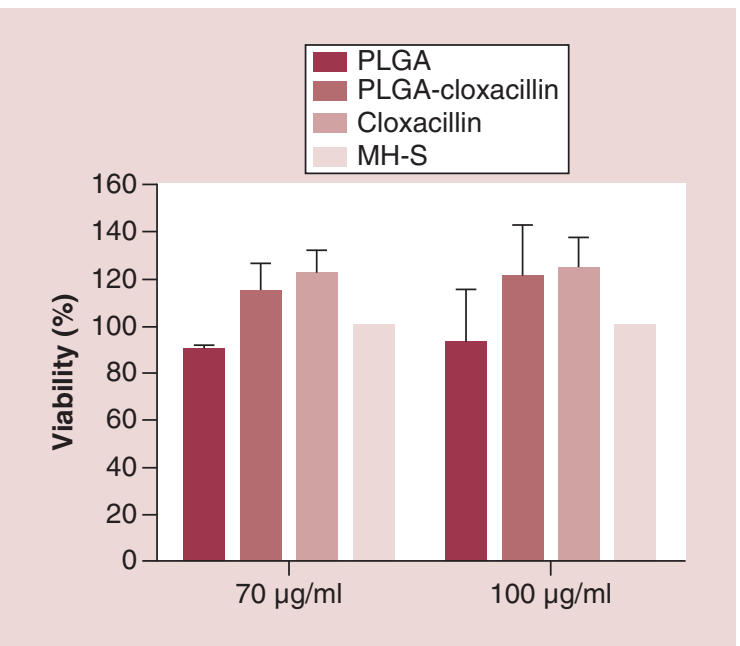

Figure 4. Cytotoxicity of poly(D,L-lactide-co-glycolide) acid nanoparticles on $\mathrm{MH}-\mathrm{S}$ cell line assessed with Presto Blue. Controls represent $100 \%$ viability.

MH-S: Alveolar macrophage cell line (control); PLGA: Poly(D,L-lactide-co-glycolide).

comparison to the use of the free-drug, suggesting that the encapsulated drug at the lowest concentration tested is more effective at eliminating the intracellular bacterial burden. For the highest concentration $(60 \mu \mathrm{g} / \mathrm{ml})$, there was an overlap of bacterial counts at $24.5 \mathrm{~h}$ post-infection, with no differences between concentrations or cloxacillin presentation (free or encapsulated).

\section{Discussion}

Bacterial strategies such as intracellular survival within host cells and biofilm formation may hinder the access of antimicrobials to the site of infection, reducing their activity and efficacy [21]. Indeed, S. aureus and P. aeruginosa [22] are two examples of facultative intracellular pathogens that have developed diverse bacterial mechanisms of adap- 

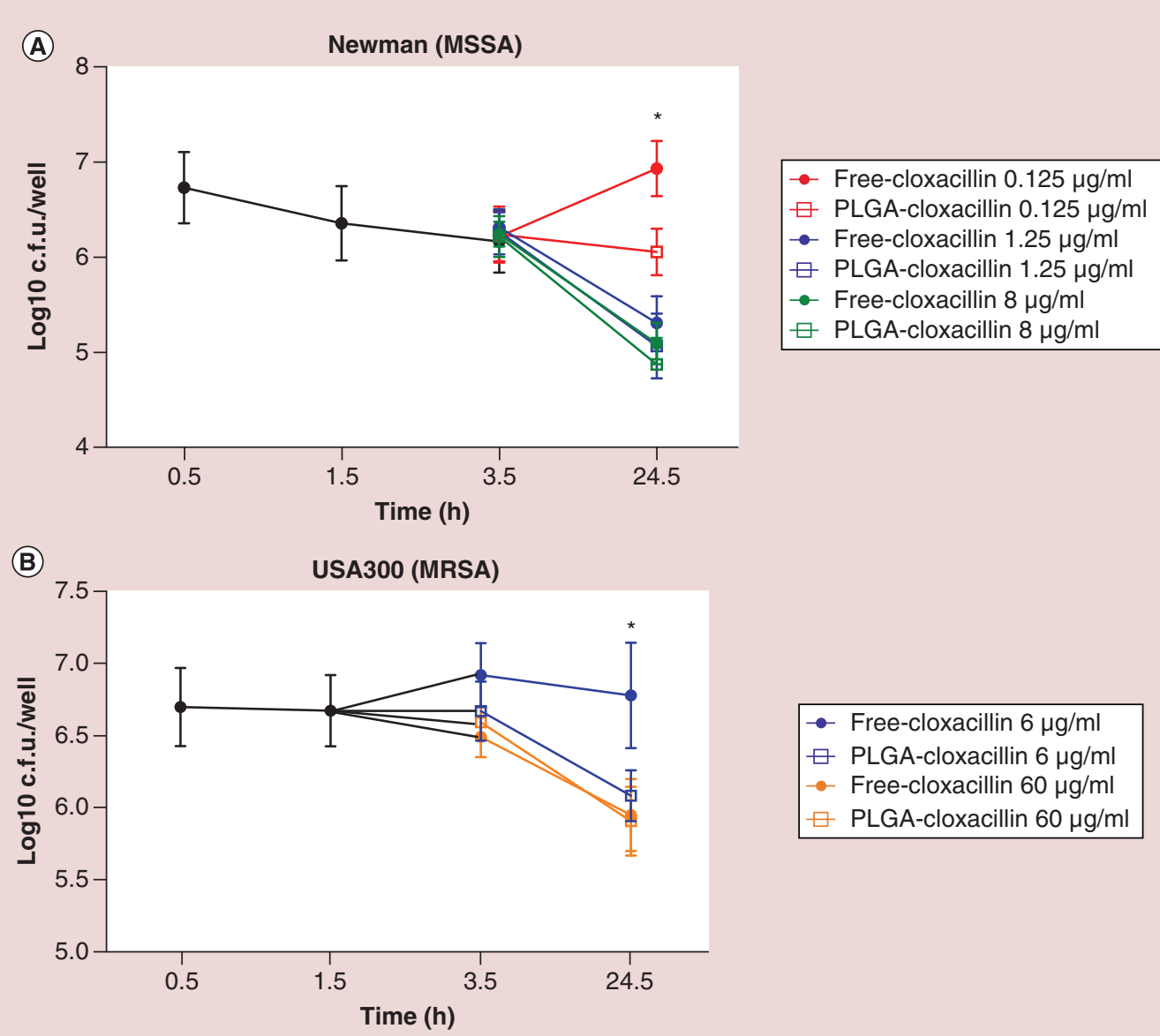

$\square$ PLGA-cloxacillin $8 \mu \mathrm{g} / \mathrm{ml}$

Figure 5. Intracellular bacterial load. (A) Time course analysis of intracellular Staphylococcus aureus Newman in infected MH-S treated with free-cloxacillin and PLGA-cloxacillin $(0.125,1.25$ and $8 \mu \mathrm{g} / \mathrm{ml})$; $\mathrm{p}<0.05$, considering $0.125 \mu \mathrm{g} / \mathrm{ml}$ at $24.5 \mathrm{~h}$ post infection, there are statistical differences between bacterial counts obtained for free-cloxacillin and PLGA-cloxacillin treated cells. (B) Time course analysis of intracellular S. aureus USA300 in infected MH-S treated with free-cloxacillin and PLGA-cloxacillin $(6$ and $60 \mu \mathrm{g} / \mathrm{ml}) ;{ }^{*} \mathrm{p}<0.05$, considering $6 \mu \mathrm{g} / \mathrm{ml}$ at $24.5 \mathrm{~h}$ post infectioon, there are statistical differences between bacterial counts obtained for free-cloxacillin and PLGA-cloxacillin treated cells.

MRSA: Methicillin-resistant Staphylococcus aureus; MSSA: Methicillin-susceptible Staphylococcus aureus; PLGA: Poly(D,L-lactide-co-glycolide).

tation during acute and chronic respiratory infections [23,24] including the alteration of virulence factor regulation, metabolic pathways and phagocytosis capacity and including the ability to form subpopulations with different phenotypes [25-27]. In addition, biofilms formed by these bacteria are associated with indwelling medical devices or structural dilatation of the bronchi. Drug-delivery systems aimed specifically at infected lung cells would improve local drug concentration and efficacy [28-30].

The continued evolution of antimicrobial resistance is a growing concern because of its potential to endanger the future of antimicrobial drug therapy. Even the new generation of antibiotics is becoming virtually ineffective and it is predicted that antimicrobial resistance will cause more deaths than cancer-associated diseases by the middle of the century [31]. In recent decades, significant progress has been made in the development of nanotechnologybased approaches to prevent, diagnose and treat human diseases. Their application is principally directed toward drug-delivery systems in cancer treatment and only recently in antimicrobial therapy [14]. Antimicrobial loaded NPs can offer some advantages over conventional antimicrobial treatments such as protection from clearance and enzymatic/chemical/surfactant inactivation, improved muco-adhesion and the ability to penetrate cell membranes [32,33] and biofilms [34], they present enhanced intracellular retention and improve the specific delivery to the site of infection. 


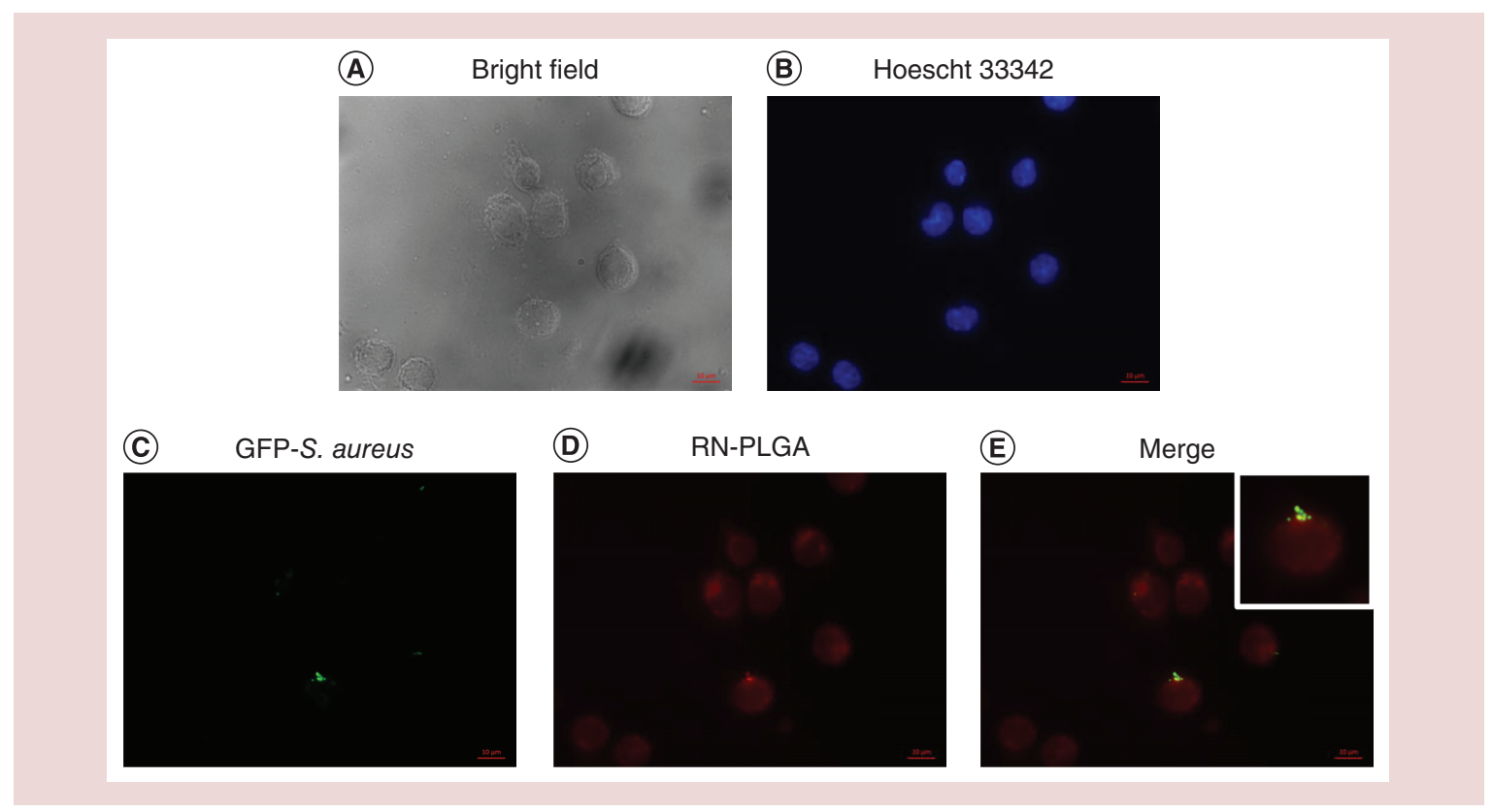

Figure 6. Representative immunofluorescence analysis. Image was taken at $1.5 \mathrm{~h}$ post infection and shows nuclei stained with Hoeschst 33342 (blue) (B), GFP- S. aureus (green) (C), RN-PLGA nanoparticle (red) (D) and merge (E). An image taken with bright field is also included (A). PLGA: Poly(D,L-lactide-co-glycolide); RN: Red Nile.

In the current work, we have shown that by using a single emulsion solvent evaporation technique, cloxacillin loaded PLGA NPs can be prepared with encapsulation efficiency $(20.5 \pm 1.2 \% \mathrm{w} / \mathrm{w})$, which is similar to what we recently demonstrated for rifampicin [17]. Using other antimicrobials, it has been previously reported that both single and double emulsion enable the preparation of drug loaded NP with high encapsulation efficiency but reduced drug loadings (DL; usually <5-10 wt.\%) [35]. For instance, Cheow et al. reported a $2.3 \mathrm{wt} . \%$ DL when encapsulating highly water and solvent-soluble levofloxacin PLGA nanoparticles using double emulsion solvent evaporation methods [36]. Amikacin loaded PLGA NPs with DLs of $2.5 \mathrm{wt} . \%$ were also prepared and successfully tested against $P$. aeruginosa [37]. Optimized PLGA NPs containing tobramycin using different surfactants and co-polymers (i.e., chitosan, alginate, PVA) rendered DLs, which varied between 0.08 and $2 \mathrm{wt} . \%$. Therefore, our results are in agreement with the literature and confirm that emulsion solvent evaporation methods are very simple synthesis processes, which allow the successful encapsulation of both hydrophilic and hydrophobic drugs with reasonably high drug loadings.

Regarding the antimicrobial activity of cloxacillin loaded NPs, MICs were determined at pH 7, 5.5 and 4.5 as these nanoparticles are designed to release their content under intracellular acidic conditions. The different $\mathrm{pHs}$ studied were chosen to give an idea of the antimicrobial efficiency under extracellular conditions $(\mathrm{pH} 7)$ and intracellular conditions: late endosomes ( $\mathrm{pH} \sim 5.5$ ) and lysosomes ( $\mathrm{pH} \sim 4.5)$. Considering both strains (MRSA and MSSA), MICs obtained for PLGA-cloxacillin loaded NPs were lower than those obtained for the free drug at all $\mathrm{pHs}$ tested, indicating a higher bactericidal activity. Particularly for $\beta$-lactams (such as cloxacillin), this improvement in activity when the drug is encapsulated could be relevant from a clinical perspective. The intracellular activity of cloxacillin is low, so developing a system that would deliver the antimicrobial protected within a nanoparticle into a tissue with evidence of $S$. aureus persistence represents an interesting approach. It is widely known that $\beta$-lactams are time-dependent antibiotics, and thus more effective if their concentration is above MIC values for longer times, in comparison to other antibiotics that require a maximum concentration (concentration-dependent antibiotic) such as aminoglycosides. According to the release kinetics assay (Figure 1G) the drug release from the nanoparticles was sustained for long periods of time, which could contribute to the efficient bacterial eradication observed. Sustained drug release into the media would protect, preserve and promote antimicrobial activity as the NPs are degraded. Interestingly, USA300 was categorized as methicillin-susceptible in the presence of acidic and neutral $\mathrm{pH}$ when treated with cloxacillin-PLGA NP. A similar observation was also reported by Lemaire $e t a l$. [38], 
who found that MRSA are as susceptible as MSSA in broth at acidic $\mathrm{pH}$. As previously mentioned, $S$. aureus is able to reside intracellularly in different cell types using multiple strategies [9,39]. Indeed it is known to adapt to different anatomical niches, with a high level of tolerance to habitats with $\mathrm{pH}$ changes, such as the nares and the lungs [24]. Particularly within murine alveolar macrophages, $S$. aureus replicates and remains viable in an acidic subcellular compartment, which colocalizes with late endosome markers [11]. It is known that the $\mathrm{pH}$ of phagolysosomes in macrophages is about 5 [40]. Interestingly, at acidic conditions $S$. aureus PBP2a suffers conformational changes that renders it more susceptible to $\beta$-lactams [41]. Thus, we evaluated the antimicrobial activity of cloxacillin loaded NPs in MH-S infected with two strains (Newman and USA300). Three different concentrations of drug loaded NPs and free drug (corresponding to MIC, $10 \times$ MIC, respectively for each strain and human serum $\mathrm{C}_{\max }$ ) were tested. When considering the Newman strain, the highest reduction of intracellular bacterial load was observed for the highest concentration of drug tested $(8 \mu \mathrm{g} / \mathrm{ml})$, although no differences between encapsulated/free cloxacillin were found. In contrast, for the lowest concentration tested $(0.125 \mu \mathrm{g} / \mathrm{ml})$, differences between the encapsulated and non-encapsulated drug were reported. When considering USA300, the highest reduction of bacterial burden was also reported for the lowest concentration of PLGA loaded cloxacillin NPs $(6 \mu \mathrm{g} / \mathrm{ml})$ that corresponded to MIC, suggesting that the nanoencapsulated antibiotic was more bactericidal and effective than the free drug. Lemaire et al. [42] used human macrophages infected with different MRSA isolates and showed that restoration of susceptibility to $\beta$-lactams after phagocytosis was independent of the MRSA strain (phenotype and SCC mec group), or of the cell type considered but varied according to the drug (imipenem, meropenem, oxacillin and cloxacillin), confirming their previous findings.

Empty PLGA nanoparticles had no inhibitory activity on bacterial growth in the MIC assay. However, in our previous work [17], empty PLGA-NPs showed intrinsic antituberculosis activity. This effect was attributed to the potential accelerated hydrolysis of the ester bonds of the PLGA, hence producing lactic and glycolic acids that would further acidify the media being this process autocatalytic [43]. As a consequence, increases in media acidification would in turn result in an enhanced bactericidal action against $M$. tuberculosis. In the current work, the increased efficacy of the nanoparticle loaded antibiotic compared with the free drug might be based on the increased nanoparticle uptake inside the infected cells. A potential co-localization between the intracellular pathogen and the drug loaded nanoparticle could also be responsible for that increased efficacy. This effect has also been previously reported. For instance Kalluru et al. [44] demonstrated that even though rifampicin-loaded PLGA-NPs were able clear macrophages infected with Mycobacterium bovis more efficiently compared with the administration of the free drug, the drug-containing NPs remained inside phagolysosomes that were separated from the BCG-containing phagosomes. The authors postulated that the loaded hydrophobic drugs easily crossed by diffusion, both the phagolysosome membrane enclosing the NP (phagosome to cytoplasm) and the membrane of the phagosome enclosing the BCG.

In recent years, different nano-based strategies for treating $S$. aureus infections have been designed [15,45]. Immunofluorescence analysis has shown that RN-PLGA NPs are internalized within infected cells, and that they can co-localize with bacteria. Thus, drug loaded PLGA nanoparticles that have the same characteristics might also be internalized and so that the drug would be released inside the cell. It is reasonable to speculate that although not all NPs internalized by infected MH-S will co-localize within the same vesicle where $S$. aureus resides, drug diffusion into the cytosol can also facilitate the clearing of the infection. Indeed according to the cellular infection model and isolate considered, bacteria are also able to escape from phagosome compartments and survive in the cytosol of infected cells [46]. Accordingly, intracellular accumulation and slow antibiotic release could also potentially improve bacterial eradication. A similar approach to our proposal against MRSA infected macrophages was reported when using particles engineered with vancomycin that showed better antimicrobial activity for the loaded NPs than for the free drug in cell culture invasion and animal models [47]. One promising example developed by Abed et al. [48] is aimed at intracellular bacteria by means of a nanosystem coupled to gentamicin, which acted as a prodrug, with a high drug payload and specific antibiotic delivery in infected intracellular compartments. Lehar et al. [49] designed and evaluated, a novel anti-S. aureus antibody-vancomycin conjugate that was able to eliminate intracellular $S$. aureus in a mouse model. Specifically, the drug was released in the presence of acidic $\mathrm{pH}$, once inside the $S$. aureus containing phagolysosome. Another option is the use of mesoporous silica gentamicin loaded nanoparticles within a lipidic bilayer shell [50] that provided an effective inhibition in vitro and in vivo of planktonic and intracellular $S$. aureus bacterial growth. Interestingly, drug loaded NPs also down regulated inflammation-related gene expression in infected cells. 


\section{Conclusion}

MICs for PLGA-cloxacillin NPs are lower than those obtained with free-cloxacillin both for MSSA and MRSA isolates. Cloxacillin loaded NPs show antimicrobial activity at acidic and neutral $\mathrm{pH}$ and a sustained and controlled antibiotic release could be expected when using the drug-loaded encapsulated NP. In cell infection models, the use of drug loaded NPs enabled a bigger reduction of intracellular bacterial load. Thus, this novel delivery system shows a great potential for the successful targeted treatment of staphylococcal infections due to its capacity for drug intracellular delivery and release, coupled with its high cytocompatibility.

\section{Future perspective}

The increase of antibiotic resistant bacteria is a rising concern worldwide. The use of nanotechnological approaches can improve current antimicrobial treatments by providing a rational usage of antibiotics. Targeted therapies based on drug-loaded NPs with demonstrated benefits over the administration of the free drug will direct future research lines. Interestingly, Staphylococcus aureus is mostly localized in the extracellular milieu but has also been found intracellularly in different cell types. The delivery of antimicrobials into infected cells using drug-loaded nanoparticles thus represents a novel strategy. Future research following the study reported here will be directed toward the in vivo evaluation of the effect of the antibiotic-loaded NPs compared with the administration of the free drug in mice infected with methicillin-susceptible and resistant $S$. aureus strains.

\section{Summary points}

- The encapsulation procedure did not hinder the antimicrobial action of the encapsulated antibiotic cloxacillin.

- Drug encapsulation improves antimicrobial activity of cloxacillin against S. aureus isolates.

- Sustained antibiotic release is reported when using drug-loaded nanoparticles.

- The nanoparticles eliminated both methicillin-resistant and -susceptible strains.

- Cloxacillin loaded nanoparticles have antimicrobial activity intra- and extracellularly.

- The use of drug loaded NPs enabled a greater reduction of intracellular bacterial load.

- The potential colocalization of the drug-loaded NPs with the intracellular pathogen in the same intracellular vesicle represents a promising approach to improve antibiotic therapeutic efficacy in the treatment of the disease.

\section{Author contributions}

A Lacoma, G Mendoza, V Sebastián, J Domínguez, M Arruebo and C Prat were responsible of conception and design of study. A Lacoma, L Usón, E Garcia-Garcia and B Muriel-Moreno were responsible of laboratory data acquisition. A Lacoma, L Usón, J Domínguez, M Arruebo and C Prat were responsible of data analysis. A Lacoma, G Mendoza, V Sebastián, J Domínguez, M Arruebo and $C$ Prat were responsible of article drafting and critical revision. All authors approved the final version of the manuscript.

\section{Acknowledgments}

The authors thank M Giménez and R Villar-Hernández for helpful discussion of the results. The authors thank the IGTP Microscopy Core Facility and staff (MP Armengol and G Requena) for their contribution to this publication. The synthesis of materials has been performed by the Platform of Production of Biomaterials and Nanoparticles of the NANOBIOSIS ICTS (Nanoparticle Synthesis Unit). The authors are grateful to LMA-INA (University of Zaragoza, Spain) for their instruments and expertise.

\section{Financial \& competing interests disclosure}

This project was funded jointly by SEPAR (Spanish Society for Pneumology and Thoracic Surgery), CIBER-BBN and CIBERES (Spanish Consortia for Research on Bioengineering, Biomaterials and Nanomedicine, and on Respiratory Diseases, respectively). This research was also supported by the Instituto de Salud Carlos III (PI 17/01139), integrated in the Plan Nacional de I+D+I and co-funded jointly by the ISCIII Subdirección General de Evaluación and the Fondo Europeo de Desarrollo Regional (FEDER). We also thank the support from The Spanish Ministry of Science, Innovation and Universities (grant: CTQ2017-84473-R). We also acknowledge financial support from the EU (ERC Consolidator grant program, ERC-2013-CoG-614715, NANOHEDONISM). J Domínguez and G Mendoza are researchers from the Miguel Servet Program. C Prat was awarded by Programa Germans Trias Sapiens-Fundació Catalunya la Pedrera and European Respiratory Society - ERS Short-Term Research Fellowship 2018 (STRTF201810-00467). The authors have no other relevant affiliations or financial involvement with any organization or entity with a financial interest in or financial conflict with the subject matter or materials discussed in the manuscript apart from those disclosed.

No writing assistance was utilized in the production of this manuscript. 


\section{Open access}

This work is licensed under the Creative Commons Attribution 4.0 License. To view a copy of this license, visit http://creativecomm ons.org/licenses/by/4.0/

\section{References}

Papers of special note have been highlighted as: • of interest; $\bullet \bullet$ of considerable interest

1. Tong SY, Davis JS, Eichenberger E, Holland TL, Fowler VG Jr. Staphylococcus aureus infections: epidemiology, pathophysiology, clinical manifestations, and management. Clin. Microbiol. Rev. 28(3), 603-661 (2015).

2. World Health Organization. Antibacterial agents in clinical development: an analysis of the antibacterial clinical development pipeline, including tuberculosis. WHO/EMP/IAU/2017.11 (2017). www.who.int/medicines/areas/rational_use/antibacterial_agents_clinical_dev elopment/en/

3. European Centre for Disease Prevention and Control. Antimicrobial resistance surveillance in Europe 2018. Annual Report of the European Antimicrobial Resistance Surveillance Network,

(EARS-Net). www.ecdc.europa.eu/en/publications-data/surveillance-antimicrobial-resistance-europe-2018

4. Bru JP, Garraffo R. Role of intravenous cloxacillin for inpatient infections. Med. Mal. Infect. 42(6), 241-246 (2012).

5. Parker D, Ahn D, Cohen T, Prince A. Innate immune signaling activated by MDR bacteria in the airway. Physiol. Rev. 96(1), 19-53 (2016).

6. Coates T, Bax R, Coates A. Nasal decolonization of Staphylococcus aureus with mupirocin: strengths, weaknesses and future prospects. J. Antimicrob. Chemother. 64(1), 9-15 (2009).

7. Lacoma A, Gomes-Fernandes M, Mesalles E, Armestar F, Prat C. Persistent isolation of Staphylococcus aureus in mechanically ventilated patients: impact of host-pathogen factors on outcome. Arch. Bronconeumol. 55(3), 158-160 (2019).

8. Spaan AN, Surewaard BG, Nijland R, Van Strijp JA. Neutrophils versus Staphylococcus aureus: a biological tug of war. Annu. Rev. Microbiol. 67, 629-650 (2013).

9. Flannagan RS, Heit B, Heinrichs DE. Antimicrobial mechanisms of macrophages and the immune evasion strategies of Staphylococcus aureus. Pathogens 4(4), 826-868 (2015).

10. Loffler B, Tuchscherr L, Niemann S, Peters G. Staphylococcus aureus persistence in non-professional phagocytes. Int. J. Med. Microbiol. 304(2), 170-176 (2014).

11. Lacoma A, Cano V, Moranta D et al. Investigating intracellular persistence of Staphylococcus aureus within a murine alveolar macrophage cell line. Virulence 8(8), 1761-1775 (2017).

12. Jubrail J, Morris P, Bewley MA et al. Inability to sustain intraphagolysosomal killing of Staphylococcus aureus predisposes to bacterial persistence in macrophages. Cell. Microbiol. 18(1), 80-96 (2016).

13. Carryn S, Chanteux H, Seral C, Mingeot-Leclercq MP, Van Bambeke F, Tulkens PM. Intracellular pharmacodynamics of antibiotics. Infect. Dis. Clin. North Am. 17(3), 615-634 (2003).

14. Zaidi S, Misba L, Khan AU. Nano-therapeutics: a revolution in infection control in post antibiotic era. Nanomedicine 13(7), 2281-2301 (2017).

15. Abed N, Couvreur P. Nanocarriers for antibiotics: a promising solution to treat intracellular bacterial infections. Int. J. Antimicrob. Agents. 43(6), 485-496 (2014).

- In this review, authors describe different strategies for the delivery of antimicrobials into infected cells.

16. Griffiths G, Nystrom B, Sable SB, Khuller GK. Nanobead-based interventions for the treatment and prevention of tuberculosis. Nat. Rev. Microbiol. 8(11), 827-834 (2010).

17. Andreu V, Larrea A, Rodriguez-Fernandez $\mathrm{P}$ et al. Matryoshka-type gastro-resistant microparticles for the oral treatment of Mycobacterium tuberculosis. Nanomedicine (Lond.) 14(6), 707-726 (2019).

18. Mendoza G, Regiel-Futyra A, Andreu V et al. Bactericidal effect of gold-chitosan nanocomposites in coculture models of pathogenic bacteria and human macrophages. ACS Appl. Mater. Interfaces 9(21), 17693-17701 (2017).

19. The Sanford Guide. To Antimicrobial Therapy 2018 48th Edition. Gilbert DN, Chambers HF, Saag MS, Pavia AT, Black D, Boucher H, Freedman DO, Kim K, Schwartz BS (Eds). Antimicrobial Therapy, Inc, VA, USA (2018).

20. Ortiz De Solorzano I, Uson L, Larrea A, Miana M, Sebastian V, Arruebo M. Continuous synthesis of drug-loaded nanoparticles using microchannel emulsification and numerical modeling: effect of passive mixing. Int. J. Nanomedicine 11, 3397-3416 (2016).

21. Prat C, Lacoma A. Bacteria in the respiratory tract-how to treat? Or do not treat? Int. J. Infect. Dis. 51, 113-122 (2016).

22. Faure E, Kwong K, Nguyen D. Pseudomonas aeruginosa in chronic lung infections: how to adapt within the host? Front. Immunol. 9 , 2416 (2018).

23. Cullen L, McClean S. Bacterial adaptation during chronic respiratory infections. Pathogens 4(1), 66-89 (2015). 
24. Dastgheyb SS, Otto M. Staphylococcal adaptation to diverse physiologic niches: an overview of transcriptomic and phenotypic changes in different biological environments. Future Microbiol. 10, 1981-1995 (2015).

25. Kim W, Hendricks GL, Tori K, Fuchs BB, Mylonakis E. Strategies against methicillin-resistant Staphylococcus aureus persisters. Future Med. Chem. 10(7), 779-794 (2018).

26. Evans TJ. Small colony variants of Pseudomonas aeruginosa in chronic bacterial infection of the lung in cystic fibrosis. Future Microbiol. 10(2), 231-239 (2015).

27. Kahl BC. Small colony variants (SCVs) of Staphylococcus aureus - a bacterial survival strategy. Infect. Genet. Evol. 21, 515-522 (2014).

28. Lee WH, Loo CY, Traini D, Young PM. Nano- and micro-based inhaled drug delivery systems for targeting alveolar macrophages. Expert. Opin. Drug. Deliv. 12(6), 1009-1026 (2015).

- In this review, authors focus on the use of specific delivery of drug-loaded nanosystems in lung cell lines.

29. Moreno-Sastre M, Pastor M, Salomon CJ, Esquisabel A, Pedraz JL. Pulmonary drug delivery: a review on nanocarriers for antibacterial chemotherapy. J. Antimicrob. Chemother. 70(11), 2945-2955 (2015).

30. Ho DK, Nichols BLB, Edgar KJ, Murgia X, Loretz B, Lehr CM. Challenges and strategies in drug delivery systems for treatment of pulmonary infections. Eur. J. Pharm. Biopharm. 144, 110-124 (2019).

- In this review, authors present the current challenges for the treatment of lower respiratory tract infections and describe specific novel strategies.

31. Tackling drug-resistant infections globally: final report and recommendations. The review on antimicrobial resistance, chaired by Jim O’Neill (2016). https://amr-review.org/

32. Pal I, Bhattacharyya D, Kar RK, Zarena D, Bhunia A, Atreya HS. A peptide-nanoparticle system with improved efficacy against multidrug resistant bacteria. Sci. Rep. 9(1), 4485 (2019).

33. Thaya R, Malaikozhundan B, Vijayakumar S et al. Chitosan coated $\mathrm{Ag} / \mathrm{ZnO}$ nanocomposite and their antibiofilm, antifungal and cytotoxic effects on murine macrophages. Microb. Pathog. 100, 124-132 (2016).

34. Mu H, Tang J, Liu Q, Sun C, Wang T, Duan J. Potent antibacterial nanoparticles against biofilm and intracellular bacteria. Sci. Rep. 6, 18877 (2016).

35. Xu J, Zhang S, Machado A et al. Controllable microfluidic production of drug-loaded PLGA nanoparticles using partially water-miscible mixed solvent microdroplets as a precursor. Sci. Rep. 7(1), 4794 (2017).

36. Cheow WS, Hadinoto K. Enhancing encapsulation efficiency of highly water-soluble antibiotic in poly(lactic-co-glycolic acid) nanoparticles: modifications of standard nanoparticle preparation methods. Colloids Surfaces A: Physicochem. Engineer. Aspects 370(1-3), 79-86 (2010).

37. Sabaeifard P, Abdi-Ali A, Soudi MR, Gamazo C, Irache JM. Amikacin loaded PLGA nanoparticles against Pseudomonas aeruginosa. Eur. J. Pharm. Sci. 93, 392-398 (2016).

38. Lemaire S, Van Bambeke F, Mingeot-Leclercq MP, Glupczynski Y, Tulkens PM. Role of acidic pH in the susceptibility of intraphagocytic methicillin-resistant Staphylococcus aureus strains to meropenem and cloxacillin. Antimicrob. Agents Chemother. 51(5), 1627-1632 (2007).

39. Fraunholz M, Sinha B. Intracellular Staphylococcus aureus: live-in and let die. Front. Cell. Infect. Microbiol. 2, 43 (2012).

40. Ohkuma S, Poole B. Fluorescence probe measurement of the intralysosomal $\mathrm{pH}$ in living cells and the perturbation of $\mathrm{pH}$ by various agents. Proc. Natl Acad. Sci. USA 75(7), 3327-3331 (1978).

41. Lemaire S, Fuda C, Van Bambeke F, Tulkens PM, Mobashery S. Restoration of susceptibility of methicillin-resistant Staphylococcus aureus to beta-lactam antibiotics by acidic pH: role of penicillin-binding protein PBP 2a. J. Biol. Chem. 283(19), 12769-12776 (2008).

42. Lemaire S, Olivier A, Van Bambeke F, Tulkens PM, Appelbaum PC, Glupczynski Y. Restoration of susceptibility of intracellular methicillin-resistant Staphylococcus aureus to beta-lactams: comparison of strains, cells, and antibiotics. Antimicrob. Agents Chemother. 52(8), 2797-2805 (2008).

-• Demonstrates that restoration of methicillin-resistant Staphylococcus aureus susceptibility to beta-lactams after phagocytosis is independent of the strain and the types of cells but varies between beta-lactams.

43. Lawlor C, O'Connor G, O'Leary S et al. Treatment of Mycobacterium tuberculosis-Infected macrophages with poly(lactic-co-glycolic acid) microparticles drives NF kappa B and autophagy dependent bacillary killing. PLoS ONE 11(2), e0149167 (2016).

44. Kalluru R, Fenaroli F, Westmoreland D et al. Poly(lactide-co-glycolide)-rifampicin nanoparticles efficiently clear Mycobacterium bovis BCG infection in macrophages and remain membrane-bound in phago-lysosomes. J. Cell Sci. 126(Pt 14), 3043-3054 (2013).

45. Zhou K, Li C, Chen D et al. A review on nanosystems as an effective approach against infections of Staphylococcus aureus. Int. J. Nanomed. 13, 7333-7347 (2018).

-. Presents the current novel approaches based on nanosystems for the treatment of of staphylococcal infections.

46. Grosz M, Kolter J, Paprotka K et al. Cytoplasmic replication of Staphylococcus aureus upon phagosomal escape triggered by phenol-soluble modulin alpha. Cell. Microbiol. 16(4), 451-465 (2014).

47. Pei Y, Mohamed MF, Seleem MN, Yeo Y. Particle engineering for intracellular delivery of vancomycin to methicillin-resistant Staphylococcus aureus (MRSA)-infected macrophages. J. Control. Rel. 267, 133-143 (2017). 
-. Represents a clear example of how intracellular colocalization of the antibiotic and the pathogen renders a better antimicrobial action than the administration of the free drug.

48. Abed N, Said-Hassane F, Zouhiri F et al. An efficient system for intracellular delivery of beta-lactam antibiotics to overcome bacterial resistance. Sci. Rep. 5, 13500 (2015).

49. Lehar SM, Pillow T, Xu M et al. Novel antibody-antibiotic conjugate eliminates intracellular S. aureus. Nature 527(7578), 323-328 (2015).

50. Yang S, Han X, Yang Y et al. Bacteria-targeting nanoparticles with microenvironment-responsive antibiotic release to eliminate intracellular Staphylococcus aureus and associated infection. ACS. Appl. Mater. Interfaces 10(17), 14299-14311 (2018). 